Tropical Journal of Pharmaceutical Research, August 2009; 8 (4): 297-302

(C) Pharmacotherapy Group,

Faculty of Pharmacy, University of Benin

Benin City, 300001 Nigeria.

All rights reserved.

Research Article

Available online at http://www.tjpr.org

\title{
Knowledge, Attitude and Practice of Commercial Drivers in Dar es Salaam with Regard to Medicines that Impair Driving
}

\section{Godeliver AB Kagashe* and Khamis Seleman}

Department of Pharmaceutics, School of Pharmacy, Muhimbili University of Health and Allied Sciences, PO Box 65577, Dar es Salaam, Tanzania

\begin{abstract}
Purpose: The objective of this study was, first, to assess the knowledge, attitude and practice of commercial drivers in Dar es Salaam with regard to medicines that impair driving, and second, to evaluate the adequacy of antihistamine label information.

Methods: Drivers were interviewed using a questionnaire after obtaining their informed consent. Labels of medicines containing antihistamines were also evaluated for information regarding driving.

Results: Fifty one percent ( $n=303)$ of drivers were not aware of medicines that impair driving. Out of those who used medicines impairing driving, $56.1 \%$ were not given precaution on the impairing effect of these medications by healthcare providers. Fifty two percent of the drivers did not know what to do when affected; 29.8\% said they would continue driving while 16.2\% would suspend driving. Drowsiness, fatigue and blurred vision were mentioned as the main effects that impaired driving. Cough syrups (64.7\%), antimalarials (49.5\%) and analgesics (28.7\%) were mentioned most as medicines affecting driving. Labels on products containing equal concentrations of antihistamines revealed inconsistency in driving information with some products having cautionary information on driving while others had none.

Conclusion: This study showed that most of the drivers interviewed had taken medications which impaired their driving but did not know what to do. These drivers were not well informed about the effects of these medicines on driving. There is need, therefore, to inform the public about medications that impair driving. This may help in reducing road traffic accidents which are on the increase since one of the causal factors may be the intake of such medicines.
\end{abstract}

Key words: Driving impairment, Medication information, Antihistamines, Dar es Salaam 


\section{INTRODUCTION}

Driving is a psychomotor activity that requires a combination of concentration and good visual and auditory functions. Several factors can affect driving including the use of alcohol and certain medications.

The effect of alcohol on driving is well known ${ }^{1,2}$. Most drivers are at least aware that it is dangerous to drink and drive and in many countries driving while drunk is illegal ${ }^{2}$.

The effect of medicines on driving on the other hand is not well known to the public and to drivers in particular. Several studies have shown that a variety of medicines when taken can affect the mental and physical skills needed for safe driving. Some of these medicines include antihistamines which are well known for causing sedation and drowsiness ${ }^{4}$ antidepressants, benzodiazepines, antiepileptic $\operatorname{drugs}^{5,6}$. Others include antimalarials, for example, Sulphadoxine/Pyrimethamine (SP) which cause tiredness and depression, quinine and chloroquine which impair vision and hearing respectively $^{7}$. When medicines affecting driving are being prescribed and or dispensed, it is always assumed that medical personnel will give all the necessary information and instructions to the patient. Studies however, have shown that actually counseling of patients on medications is not done properly and in some cases it is not done at all $^{8,9}$. In case of over the counter drugs, it is assumed that the patient will read the label containing a warning on driving and follow the instructions properly. Studies, however, have shown that patients do not often read labels on medicine packages and even if they read sometimes, they do not understand $^{10}$. At times the warnings are ambiguous. Users of most of these medicines are ambulatory patients who can drive a car. This puts them at risk if proper instructions or warning are not provided by the health workers in particular dispensers of medicines in pharmacies.
In Tanzania, to the best of our knowledge, no studies that have been undertaken to assess medicine use and driving.

This work therefore was carried out to assess the knowledge, attitudes and practice of commercial drivers in Dar es Salaam Region regarding medicines impairing driving. The study also investigated whether drivers obtain information and warning from prescribers/dispensers about the driving impairment effect of medicines. In addition the study evaluated the adequacy of antihistamine label information.

\section{METHODS}

This was a cross sectional study which involved the following drivers in Dar es Salaam region; drivers of commuter buses known as 'dala dala' within Dar es Salaam city, taxi drivers, long distance lorry drivers and inter- regional bus drivers. Drivers from each of the above categories were interviewed face to face using questionnaire after obtaining a verbal consent from the individual driver. The questionnaire was developed and pre-tested in 15 drivers. Drivers to be interviewed were selected randomly at their packing stations

Ethical clearance for the study was obtained from the School of Pharmacy Research Committee, a subcommittee of Muhimbili University of Health and Allied Sciences (MUHAS) Research and Publication Committee, which has the mandate for granting ethical approval. Permission to interview drivers was obtained from the Drivers' Association in Dar es Salaam.

Data analysis was carried out using Epi Info software, version 6 .

\section{RESULTS}

Three hundred and three drivers (303) out of 384 drivers approached for the study agreed to participate. All 303 drivers interviewed were males (Table 1). Forty two percent were 
in the age range of $36-45$ years. Their driving experience was from 2 to more than 10 years with most drivers $(63 \%)$ having more than six years of experience. Fifty one percent $(51.5 \%)$ of drivers were unaware of the existence of medicines that impair driving. Table 2 shows medicines that impair driving as mentioned by drivers. Cough medications were high on the list (64.7\%).

Table 1: Demographic features of the study population

\begin{tabular}{ll}
\hline Characteristics & $\begin{array}{l}\text { Frequency }(\%) \\
\mathrm{n}=303\end{array}$ \\
\hline Age (years) & $2(0.7)$ \\
$<20$ & $42(13.9)$ \\
$20-25$ & $79(26.0)$ \\
$26-35$ & $126(41.6)$ \\
$36-45$ & $26(8.6)$ \\
$>45$ & $28(9.2)$ \\
No response & $121(39.9)$ \\
Education Level & $80(26.4)$ \\
Primary Education & $20(6.6)$ \\
O- Level & $38(12.5)$ \\
A- Level & $44(14.5)$ \\
College level & \\
No response &
\end{tabular}

Table 2: Medicines affecting driving as mentioned by drivers $(n=303)$

\begin{tabular}{ll}
\hline Medication & Frequency (\%) \\
\hline Cough syrups & $196(64.7)$ \\
Anti malaria drugs & $150(49.5)$ \\
Medicines used for & $66(21.8)$ \\
colds & \\
Antihypertensive & $21(6.9)$ \\
Hypnotics & $37(12.2)$ \\
Pain killers & $87(28.7)$ \\
Antiepileptic & $2(0.7)$ \\
\hline
\end{tabular}

Regarding the effects that impaired driving drowsiness $(72 \%)$ due to medications was mentioned by many drivers. Forty one percent mentioned fatigue as one of the effects impairing driving while $12 \%$ mentioned blurred vision. Table 3 shows the type of side effects experienced most and the type of medications taken. For cough syrups, drowsiness $(38 \%)$ was common while with antimalarials fatigue (36\%) was the main effect felt. When asked whether they read labels of medications. Sixty eight percent of drivers said they read labels on containers of medicines. Forty two percent $(42 \%)$ of the drivers read labels in order to get information on how to use the medication, while $42 \%$ looked out for a warning and about 4\% looked out for the content. Most drivers $(52 \%)$ said they did not know what to do when affected by medication-impaired driving.

Analysis of information on labels of different brands of medications for cough and colds, revealed that brands with the same concentration of the active ingredient affecting driving had different instructions/warnings on driving. Some products carried the warning while others of the same concentration did not. The products examined contained the same antihistamines of the same strength (Table 4).

Table 3: Side effects experienced by those who took cough syrups and antimalarial medicines

\begin{tabular}{lcc}
\hline Side effect & $\begin{array}{c}\text { Cough syrup } \\
\text { Frequency (\%) } \\
\mathrm{n}=196)\end{array}$ & $\begin{array}{l}\text { Antimalarials } \\
\text { Frequency } \\
\mathrm{n}=150\end{array}$ \\
\hline Drowsiness & $75(38.3)$ & - \\
Dizziness & $8(4.1)$ & $8(5.3)$ \\
Fatigue & $45(23.0)$ & $54(36.0)$ \\
Itching & $2(1.0)$ & $5(3.3)$ \\
Sedation & $6(3.0)$ & - \\
Blurred vision & - & $25(16.7)$ \\
Can not explain & $122(62.2)$ & $68(45.0)$ \\
\hline
\end{tabular}

\section{DISCUSSION}

Use of medicines that impair driving was reported among the population of drivers studied. Drivers who were aware of the existence of medicines that impair driving had this knowledge from experience, i.e., they had used the medicines and they were affected.

Cough syrups were the most mentioned drugs. Some drivers were able to mention specific brands of cough syrups all of which 
Table 4: Information on labels of containers of medicines containing antihistamine

\begin{tabular}{lcc}
\hline Strength & Number of product brand & Label information \\
\hline Chloropheniramine & 4 & Warning on driving \\
$2 \mathrm{mg}$ & 2 & \\
$4 \mathrm{mg}$ & 1 & No warning \\
$1 \mathrm{mg}$ & 3 & \\
$2 \mathrm{mg}$ & & Warning on driving \\
Diphenhydramine & 3 & \\
$25 \mathrm{mg}$ & 4 & \\
$14 \mathrm{mg}$ & 3 & \\
$12 \mathrm{mg}$ & 1 & No warning \\
$8 \mathrm{mg}$ & 1 & \\
$7 \mathrm{mg}$ & 2 & Warning on driving \\
$2.2 \mathrm{mg}$ & 4 & No warning \\
$14 \mathrm{mg}$ & 2 & \\
$5 \mathrm{mg}$ & 3 & \\
Promethazine & 2 & \\
$5 \mathrm{mg}$ & & \\
$5 \mathrm{mg}$ & & \\
\hline
\end{tabular}

were found to contain antihistamines on their labels. This finding is in agreement with other studies which have tested the effects of antihistamine on driving performance ${ }^{3}$. Use of sedating medicines has also been shown to be a risk factor in drowsy-driving crash ${ }^{11}$. The results for medicines said to affect driving are similar to the findings of McGwin et al who showed that non-steroidal anti-inflammatory drugs, benzodiazepines and angiotensin converting enzyme inhibitors were associated with increased risk of 'at fault' involvement in vehicle crashes ${ }^{12}$. In our study, nearly three out of ten of the drivers mentioned analgesics as causing driving impairment. The psychotropic effect of analgesics has also been indicated as a major causal factor of driving impairment ${ }^{13}$.

With regard to adverse effects following medications, drowsiness was the most mentioned effect and fatigue was next. These two have been classified as behavior factors that can reduce capability to drive on a short term basis and therefore cause road traffic crashes $^{14}$. Different therapeutic groups of medicines had different adverse effects that impaired driving most. For cough syrups, the most mentioned effect was drowsiness $(38.3 \%)$. This may be due to the fact that most of these cough medicines contained antihistamines which have been shown to cause sedation. For antimalarials, the most mentioned effect was fatigue and blurred vision and among medicines mentioned were quinine and chloroquine. These two drugs have been documented to affect driving due to these effects ${ }^{7}$.

Only a few of the drivers admitted to have received warnings from dispensers about effects of medicines on driving. About half said that they had never been warned on the effects of medicines on driving. This suggests that prescribers/dispensers do not give adequate medication information to patients. Prescribing guidelines laid down by International Pharmaceutical Federation $(F I P)^{15}$ state that if the drug is known to impair performance, then it is better to look for alternatives. If no alternative is possible then the patient must be advised accordingly. According to the present results patients were not advised on driving impairment of these medications. Similar results were shown in a study done by Brooke et $\mathrm{al}^{16}$ where patients were not informed about their fitness to drive. It may be assumed that the prescribers/dispensers were not aware of the dangers involved and hence the need to 
inform the patient. A study by Kelly et $\mathrm{al}^{17}$ showed that doctors' knowledge on driving restrictions and actions to be taken if a patient was not fit to drive was very poor.

Less than half of the drivers said that they read the labels but they only looked out for instructions on how to use the medication. Some looked out for warning but could not tell what the warning was against, while several others did not bother reading labels. This puts the drivers at risk especially when they obtain over-the-counter (OTC) medicines

Half of the drivers did not know what to do when they took medicines that affect driving. This shows that these drivers were not informed and that can be dangerous if the driver decided to engage in driving while under the influence of these medications.

The fact that there was a great variation in the display of warning information is of great concern. Wrong labeling can cause problems to the user, in this case the driver who may not take the necessary precautions

\section{CONCLUSION}

Medicines that affect driving are a problem to the society. Road traffic accidents are on the increase in Tanzania and one of the causal factors may be the intake of medicines that impair driving. This study has shown that most of the drivers interviewed had taken medication that could have affected their driving but did not know what to do when the medication affected adversely. This indicates that drivers were not well informed about the effects of these medicines and the actions to be taken. There is a need therefore to inform the public and raise awareness about medications impairing driving. Proper labeling of medicines affecting driving is needed in order to ensure safe use of these medicines.

\section{REFERENCES}

1. Asiamah G, Mock C, Blantary J. Understanding the knowledge and attitude of commercial drivers in Ghana regarding alcohol impaired driving. Inj Prev. 2002; 8(1): 53-56

2. D. Span. Research on knowledge, attitudes and reported behavior on drink-driving in South Wales.

http://www.druglibrary.org/schaffer/MISC/drivin g/s6p3.htm Accessed on 19th May 2008.

3. Verster JC, Volkerts ER. Antihistamines and driving ability: evidence from on-the-road driving studies during normal traffic. Ann. Allergy Asthma Immunol. 2004; 92(3): 294-303

4. Verster JC, Veldhuijzen DS, Volkerts ER. Residual effect of sleep medication on driving ability. Sleep Med Rev. 2004; 8(4): 309-325

5. Barbone F, McMaho AD, Davey PG, Morris AD, Reid IC, McDevitt DG, MacDonald TM Association of road -traffic accidents with benzodiazepine use. Lancet 1998; 352 (9137): 1331-1336

6. Ramaekers JG. Antidepressant and driver impairment: empirical evidence from a standard on-the-road test. J.Clin. Psychiatry 2003; 64(1): 20-29

7. British National Formulary 2002, British Medical Association and the Royal Pharmaceutical Society of Great Britain, UK, 2002; 43: 311-318

8. Syhakhang L, Stenson B, Wahlstrom R, Tomson G. The quality of public and private pharmacy practices. A cross sectional study in the Savannakhet province, Lao PDR. Eur J Clin Pharmacol. 2001; 57(3); 221-227.

9. Stenson B, Syhakhang L, Eriksson B, Tomson G. Real world pharmacy: assessing the quality of private pharmacy practice in the Lao People's Democratic Republic. Soc Sci Med. 2001; 52(3); 393-404

10. Davis TC, Wolf MS, Bass PF, Thompson JA, Tilson $\mathrm{HH}$, Marolee PH, Neuberger MS, Parker RM. Literacy and Misunderstanding Prescription Drug Labels. Ann.Intern.Med. 2006; 145 (12): 887-894

11. Strohl KP, Merritt SL, Blatt J, Pack Al, Council F, Rogus S, Drowsy Driving and Automobile crashes. NCCDR/NHTSA Expert Panel on Driver Fatigue and Sleepiness. www.nhtsa.dot.gov.people/injury/drowsy_drivin g1/drowsy.html. Accessed 19 May 2008

12. McGwin G Jr, Sims RV, Pulley L, Roseman JM. Relations among chronic medical conditions, medications, and automobile crush in the elderly: a population-based case-control study. Am J Epidemiol. 2000; 152(5): 424-431

13. Sohn W. Pain patient in street traffic. Do analgesics impair driving safety? MMW Fortschr Med 2003; 145(23): 37-39

14. Petridou E, Moustaki M. Human factor in the causation of road traffic crashes. Eur $J$ Epidemiol. 2000; 16(9): 819-826

15. FIP statement of professional standards on the supply of medicines affecting driving performance. www.fip.org/www/uploads/database_file.php?id $=213 \&$ table_id. Accessed June 2008.

16. Brooke BT, Southward RD. An audit on advice on fitness to drive during accident and Emergency 
Kagashe \& Seleman

Department attendance. Emerg. Med. J 2006; 23(2): 103-104
17. Kelly $R$, Warke $T$, Steele I. Medical restriction to driving: the awareness of patients and doctors. Postgrad Med J 1999; 75(887): 537-539 